\title{
DESENHO INSTITUCIONAL E JUDICIALIZAÇÃO DA POLÍTICA NAS CORTES CONSTITUCIONAIS BRASILEIRA E COLOMBIANA: UMA ANÁLISE COMPARADA
}

\author{
SYlVIA MARIA CORTÊS BONIFÁCIO DE ARAÚJO ${ }^{+}$ \\ Claudia Maria Barbosa ${ }^{+\dagger}$ \\ CAMILA SALGUEIRO dA PURIFICAÇÃo MARQUES ${ }^{+++}$
}

Resumo: A judicialização da política é um fenômeno que impacta diretamente a atuação das cortes constitucionais de diferentes países. Brasil e Colômbia compartilham semelhanças, mas distinguem-se também em aspectos importantes do exercício do controle de constitucionalidade. A partir de fatores institucionais selecionados por Tom Ginsburg, analisa-se a expansão do poder decisório das Cortes Constitucionais desses dois países, procurando-se evidenciar que o desenho institucional dessas Cortes reflete-se diretamente na forma pela qual o judicial review é exercido. A análise é feita tomando-se em conta (i) número de juízes, (ii) mandato dos juízes, (iii) mecanismos de escolha dos magistrados, (v) acesso à corte constitucional e (iv) eficácia das decisões proferidas pelas cortes. A não ser pelo mandato fixo e não renovável de seus membros, todos os outros fatores analisados demonstram uma maior independência e poder decisório da Corte Constitucional Colombiana, em relação à política, quando comparada à realidade brasileira, o que contribui para justificar sua caracterização como uma das cortes mais ativistas do mundo.

Palavras-Chave: Controle Judicial; Judicialização da Política; Corte Constitucional Colombiana; Supremo Tribunal Federal.

\footnotetext{
+ Mestranda em Direito Econômico e Socioambiental na Pontifícia Universidade Católica do Paraná. Bacharel em Direito pela Universidade Federal do Rio Grande do Norte.

${ }^{+}+$Doutora em Direito pela Universidade Federal de Santa Catarina. Professora titular de Direito Constitucional da Pontifícia Universidade Católica do Paraná.

${ }^{t+t}$ Doutoranda em Direito Econômico e Socioambiental na Pontifícia Universidade Católica do Paraná. Mestre em Direito Processual Civil pela Pontifícia Universidade Católica de São Paulo. Advogada e Professora.
} 
ABSTRACT: The judicialization of politics is a phenomenon that directly impacts the performance of the constitutional courts of different countries. Brazil and Colombia share similarities, but they also differ in important aspects of the exercise of judicial review. Based on institutional factors selected by Tom Ginsburg, the expansion of the decision-making power of the Constitutional Courts of these two countries is analyzed, seeking to show that the institutional design of these courts is directly reflected in the way judicial review is exercised. The analysis is based on (i) the number of judges, (ii) the judges' mandate, (iii) the mechanisms of appointment, (v) access to the constitutional court and (iv) the effectiveness of the decisions pronounced by the courts. Except for the fixed and non-renewable term of its members, all other factors analyzed demonstrate greater independence and decision-making power of the Colombian Constitutional Court in relation to politics, when compared to the Brazilian reality, which contributes to justify its characterization as one of the most activist courts in the world.

KeYworDs: Judicial Review; Judicialization of Politics; Constitutional Court. 
DESENHO INSTITUCIONAL E JUDICIALIZAÇÃO DA POLÍTICA NAS CORTES CONSTITUCIONAIS BRASILEIRA E COLOMBIANA

\section{INTRODUÇÃO}

O Poder Judiciário brasileiro tem assumido recentemente uma postura proativa e expansiva de interpretação da Constituição. Por meio desse fenômeno, a jurisdição constitucional tem avançado sobre a competência dos Poderes Executivo e Legislativo, proferindo decisões por diversas vezes de tendência contramajoritária e despertando a atenção não só de juristas, mas da mídia e de toda a sociedade. Essa expansão é expressão do fenômeno denominado judicialização da política.

O tema é controverso e ganhou espaço na doutrina brasileira a partir da primeira década deste século ${ }^{1}$ pela proliferação de estudos e debates midiáticos sobre a interferência entre os poderes. A matéria, entretanto, está longe de ter seu objeto esgotado - seja porque a mudança no papel da atividade da jurisdição constitucional é recente, seja pela dificuldade de sistematização em face da predominante visão subjetivista de análise das decisões do Supremo Tribunal Federal.

Alguns fatores se apresentam como, se não autorizadores, pelo menos impulsionadores do protagonismo judicial, dentre eles, destacam-se a variedade de direitos sociais e amplitude de princípios previstos na Carta Constitucional e a crise de desconfiança e representatividade popular. Sob outro prisma, são evidenciadas a falta de legitimidade democrática, a indevida politização e a limitada capacidade institucional do Poder Judiciário como objeções ao seu protagonismo².

Especificamente, deve-se ter em mente que o protagonismo do Poder Judiciário, em oposição à inércia tradicionalmente esperada, é revelado de acordo com o sistema constitucional no qual está inserido, e tem correlação direta com o papel atribuído à jurisdição constitucional na arquitetura institucional dos Poderes de Estado, e com o contexto sociopolítico em que se insere. Aqui repousa a razão pela qual o estudo comparado do fenômeno se mostra imprescindível à melhor compreensão de suas características.

Nesse sentido, o objetivo do presente artigo é identificar o papel das características institucionais das cortes constitucionais da Colômbia e do Brasil no fomento ou desestímulo à judicialização da política. Para tanto, inicialmente são apresentadas noções gerais sobre a judicialização da política na Corte Constitucional Colombiana, explicando-se brevemente

1 CAMPOS, Carlos Alexandre de Azevedo. Dimensões do Ativismo Judicial do STF. Rio de Janeiro: Forense, 2014, p. 209.

2 BARROSO, Luis Roberto. Judicialização, Ativismo Judicial e Legitimidade Democrática. [Syn]Thesis, Rio de Janeiro, v. 5, n. 1, 2012, p. 27. 
as razões pelas quais a realidade desse tribunal foi escolhida como parâmetro de comparação.

Em seguida, com o escopo de encontrar justificativas institucionais para o desenvolvimento exponencial do protagonismo judicial em ambos os países, são estabelecidos cinco critérios de comparação, retirados da obra de Tom Ginsburg, Judicial Review in New Democracies: constitutional courts in asian cases, desenvolvida para a análise das características institucionais de cortes constitucionais em períodos de transição democrática.

Os fatores institucionais estudados são (i) o número de juízes, (ii) o mandato dos juízes, (iii) os mecanismos de escolha dos magistrados, (v) o acesso à corte constitucional e (iv) a eficácia das decisões proferidas pelas cortes, sob a perspectiva comparada no Brasil e na Colômbia no período posterior após a promulgação de suas constituições democráticas, ou seja, a partir de 1988 e 1991 respectivamente, com o objetivo de entender como tais fatores influenciaram o desenvolvimento da judicialização da política naqueles Estados.

O presente artigo se concentra nos ordenamentos jurídicos vigentes no Brasil e na Colômbia, promovendo uma análise comparativa normativa e doutrinária, a fim de estabelecer as premissas teóricas do estágio atual da judicialização da política no sistema constitucional dos dois países investigados a partir do desenho institucional das suas Cortes Constitucionais.

\section{A JUdiCIALIZAÇão DA POLÍTICA NA CORTE CONSTITUCIONAL COLOMBIANA}

Desde que os trabalhos de Tate e Vallinder demonstraram a expansão mundial do poder do Judiciário, especialmente no livro The Global Expansion of Judicial Power, publicado em 1995, evidenciou-se a necessidade e utilidade do estudo comparado do comportamento das Cortes Constitucionais para ampliar a compreensão da judicialização da política.

Embora tradicionalmente ${ }^{3}$ - ao menos entre os países que adotam o sistema de civil law, como o Brasil - o estudo de cortes constitucionais no que tange ao controle de constitucionalidade das leis tenha se voltado ao "Velho Continente", especialmente ao Tribunal Constitucional Federal Alemão, há países cuja realidade exigiram das cortes constitucionais

\footnotetext{
${ }^{3}$ Os Estados Unidos, enquanto berço do ativismo judicial, também é sempre objeto de construção doutrinária.
} 


\title{
DESENHO INSTITUCIONAL E JUDICIALIZAÇÃO DA POLÍTICA NAS
}

\author{
CORTES CONSTITUCIONAIS BRASILEIRA E COLOMBIANA
}

desenhos e práxis muito mais complexas, como é o caso da Colômbia. A proximidade de contextos geográfico, histórico, político e social entre Brasil e Colômbia, torna essa análise comparativa bastante interessante e útil.

Os recentes processos constituintes latino-americanos, dentre eles o brasileiro, ocorridos entre o final do século XX e início do século XXI revelaram constituições com ampla proteção de direitos e peculiar arranjo entre os poderes. Na América Latina, com a superação de regimes autoritários, diversos países têm vivenciado a expansão da atuação de sua jurisdição constitucional e entre eles um dos principais, ao lado do Brasil, é a Colômbia, cuja corte constitucional é considerada uma das mais ativistas do mundo ${ }^{4}$.

Na Colômbia a tradição histórica do judicial review - a ação popular dirigida à Corte Suprema existe desde 1910 - apoia um expressivo protagonismo do Poder Judiciário. A crise de representatividade que parecia superada quando da união, na Assembleia Constituinte de 1991, de atores políticos e sociais tradicionalmente excluídos, revela-se ainda mais forte pela desintegração dessas forças constituintes em virtude da violência ${ }^{5}$ e corrupção que provocam a debilidade dos movimentos sociais no país. Além disso, a Constituição Política da Colômbia de 1991 e sua abrangente previsão de direitos fundamentais (artigos 11 a 41) e sociais (artigos 47 a 77), o amplo acesso à jurisdição da corte constitucional (acciones de tutela e acciones públicas - de livre propositura por qualquer cidadão, segundo os artigos $241 \S \S 1^{\circ}$ e $4^{\circ}$ e $\left.242, \S 1^{\circ}\right)$, são alguns fatores que justificam o destaque colombiano.

Manuel José Cepeda-Espinosa ${ }^{6}$ destaca três especificidades do contexto político colombiano e três características do arranjo institucional do Estado que justificam a expansão da atividade da sua corte constitucional. As razões políticas consistem em: i) presidencialismo forte e manipulador do Congresso Nacional, ii) ausência de credibilidade popular nos partidos políticos, na classe política e no Congresso Nacional e iii) uso da violência como tradicional mecanismo de resolução de conflitos no país. Somam às razões políticas as seguintes características institucionais: i) o flexível mecanismo de emendas à constituição, ii) o

${ }^{4}$ CAMPOS, Carlos Alexandre de Azevedo. Dimensões do Ativismo Judicial do STF. Rio de Janeiro: Forense, 2014, p. 31.

${ }^{5}$ ROSA, Brunna. Assassinato de Sindicalista Leva para 30 as Mortes de Líderes Políticos na Colômbia. Federação dos trabalhadores em empresas de crédito do Paraná, 2008. Disponível em: <http://www.fetecpr.org.br/assassinato-de-sindicalista-leva-para-30as-mortes-de-lideres-politicos-na-colombia/>. Acesso em: 17 jan. 2017.

${ }^{6}$ CEPEDA-ESPINOSA, M. J. Judicial Activism in a Violent Context: The Origin, Role, and Impact of the Colombian Constitutional Court. Washington University Global Studies Law Review, v. 3, n. 4, p. 529-700, 2004, p. 153. 
sistema de eleição popular indireta dos juízes da corte, através do Senado, iii) o mandato não prorrogável de oito anos dos magistrados, iv) a natureza participativa do processo decisório da corte constitucional, através das acciones públicas e da participação de especialistas nos julgamentos.

A Corte Constitucional Colombiana tem sido bastante proativa no que tange ao controle de políticas públicas e demais ações do Executivo e à defesa de direitos fundamentais, sociais e econômicos, conforme destaca o professor da Universidade Nacional da Colômbia, Rodrigo Uprimny Yepes ${ }^{7}$ :

Assim entendida, a Colômbia, nas últimas duas décadas, conheceu formas importantes de judicialização da política em numerosos campos, mas talvez os mais significativos tenham sido os seguintes: (a) a luta contra a corrupção política e pela transformação das práticas políticas; (b) o controle dos excessos governamentais, em especial nos estados de exceção; (c) a proteção de grupos minoritários e da autonomia individual; (d) a proteção de populações estigmatizadas ou em situações de debilidade manifesta e, por último, mas nem por isso menos importante; (e) a gestão da política econômica, devido à proteção judicial dos direitos sociais.

Um exemplo emblemático é o da decisão proferida em $1992^{8}$ acerca do controle de constitucionalidade das declarações de estado de exceção proferidas pelo Presidente, na qual a Corte reconheceu a discricionariedade deste para declarar quando e por quanto tempo se dará a situação de exceção, porém ampliou o espectro de controle sobre essa discricionariedade, afirmando que deveria ir além das fiscalizações procedimentais para adentrar no controle material das razões políticas da medida?.

${ }^{7}$ UPRIMNY YEPES, Rodrigo. A JUDICIALIZAÇÃO DA POLÍTICA NA COLÔMBIA: CASOS, POTENCIALIDADES E RISCOS. Sur - Revista Internacional de Direitos Humanos, v. 6, p.53-69, 2007, p. 54.

${ }^{8}$ COLÔMBIA. Corte Constitucional. Sentencia no ${ }^{\circ}$ C-004, de 07/05/1992.

9 CAMPOS, Carlos Alexandre de Azevedo. Dimensões do Ativismo Judicial do STF. Rio de Janeiro: Forense, 2014, p. 123. 
DESENHO INSTITUCIONAL E JUDICIALIZAÇÃO DA POLÍTICA NAS CORTES CONSTITUCIONAIS BRASILEIRA E COLOMBIANA

Havia muitas razões para o exercício desse controle. Dos 42 anos passados entre novembro de 1949 - quando houve o fechamento temporário do Congresso - até a promulgação da Constituição em 1991, o povo colombiano viveu 35 anos sob estado de sítio. Após a intervenção da Corte Constitucional, "o tempo vivido pelos colombianos em estados de exceção caiu de $80 \%$ na década de 80 para menos de $20 \%$ a partir da introdução desse controle judiciário, na década de 1990", segundo afirma Rodrigo Yepes Uprimny ${ }^{10}$.

A tendência progressista das decisões ${ }^{11} \mathrm{e}$ a amplitude de direitos sociais e coletivos previstos na Constituição colombiana arrematam, sem esgotar, as razões pelas quais foi feita a opção pelo estudo comparativo com a Corte Constitucional Colombiana, tomando-se esta como símbolo de um modelo no qual se privilegia a jurisdição constitucional como estratégia de emancipação social.

\section{FATORES INSTITUCIONAIS E AVANÇO DA JUDICIALIZAÇÃO DA POLÍTICA}

Acompanhando a tendência que e verificou na Europa do pós-Guerra, a Constituição Brasileira de 88, fortemente influenciada pelas Cartas da Espanha e de Portugal que resultaram dos processos de redemocratização desses países, ampliou o rol dos direitos e garantias fundamentais do cidadão e fortaleceu a jurisdição constitucional como forma de protege-los e efetiva-los. O Brasil, contudo, inovou no seu desenho institucional, compartilhando entre o Supremo Tribunal Federal e os juízes de direito, o dever de proteger e efetivar os direitos que a Constituição estabeleceu, adotando o que a doutrina chamou controle misto de constitucionalidade, que combina a um só tempo os controles difuso e concentrado, estando esse último restrito ao Supremo Tribunal Federal.

Na Colômbia o âmbito de atuação da jurisdição constitucional também foi ampliado, com as disposições constante dos artigos 239 a 245 da Constituição Política de 1991, promulgada no governo de César Gaviria Trujillo. Nese país promoveu-se uma maior participação democrática nas esferas pública e privada, criando uma série de

${ }^{10}$ UPRIMNY YEPES, Rodrigo. A JUDICIALIZAÇÃO DA POLÍTICA NA COLÔMBIA: CASOS, POTENCIALIDADES E RISCOS. Sur - Revista Internacional de Direitos Humanos, v. 6, p.53-69, 2007, p. 56.

11 BRASIL. Supremo Tribunal Federal. Notícias: Corte Constitucional da Colômbia afirma: A prostituição é um trabalho. Brasília/DF. 2017. BRASIL. Supremo Tribunal Federal. Notícias: Corte Constitucional da Colômbia entende que não se pode exigir cartão militar de pessoas transexuais. Brasília/DF. 2017. 
mecanismos e instituições para garantir a executoriedade do texto constitucional, inclusive a Corte Constitucional Colombiana.

Vários são os elementos comparativos dos sistemas brasileiro e colombiano de Judicial Review. O artigo compara fatores institucionais que possivelmente tornaram propício o desenvolvimento da judicialização da política no Supremo Tribunal Federal e na Corte Constitucional Colombiana, retirados da obra de Tom Ginsburg, Judicial Review in New Democracies: constitutional courts in asian cases, sobre cortes constitucionais estabelecidas em períodos de transição democrática. São eles: (i) o número, (ii) o mandato e (iii) os mecanismos de escolha dos magistrados da corte, e (iv) o acesso à corte constitucional e (iv) a eficácia das decisões proferidas pelas cortes.

Carlos Alexandre de Azevedo Campos, analisando os fatores estabelecidos por Tom Ginsburg, explica que os três primeiros elementos - quando considerados isoladamente, presumindo-se que os outros fatores são iguais entre as cortes comparadas - indicam maior ou menor independência das cortes, pois, segundo este autor: (i) "quanto maior o número de juízes na corte, menor será a oportunidade de influência partidária"; (ii) "quanto mais longo e seguro o mandato do juiz, mais liberdade ele terá para exercer sua missão"; (iii) "quanto menos politicamente concentrado for o poder de nomeação dos juízes, será mais provável insular os julgamentos das pressões políticas de curto prazo"12. E, em relação aos dois últimos elementos, seriam indicadores da extensão do poder decisório dos tribunais. Assim, (iv) "quanto mais descentralizado for o acesso à corte, mais amplas serão a agenda e a estrutura de oportunidades de judicialização de importantes questões políticas e sociais" e (v) "quanto mais abrangentes e vinculantes forem os efeitos das decisões, mais poder a corte exercerá sobre os demais atores e sobre a própria sociedade" 13 .

\section{Número de juízes}

O número de juízes que compõem uma corte é fator que analisa os aspectos da rapidez e precisão das decisões proferidas pelo órgão. Quanto maior o número de componentes da corte, mais lento e oneroso o processo decisório, em contrapartida, maior a probabilidade de obtenção de uma decisão mais correta e segura, uma vez consideradas mais opiniões sobre a matéria controversa.

${ }_{12}$ CAMPOS, Carlos Alexandre de Azevedo. Dimensões do Ativismo Judicial do STF. Rio de Janeiro: Forense, 2014, p. 212-213.

13 CAMPOS, Carlos Alexandre de Azevedo. Dimensões do Ativismo Judicial do STF. Rio de Janeiro: Forense, 2014, p. 213. 


\section{DESENHO INSTITUCIONAL E JUDICIALIZAÇÃO DA POLÍTICA NAS CORTES CONSTITUCIONAIS BRASILEIRA E COLOMBIANA}

Ginsburg ressalva, entretanto, que apesar de parecer plausível presumir que a possibilidade de erros diminui quando uma decisão é alcançada através da deliberação entre vários membros de um órgão ${ }^{14}$, alguns autores defendem que após um certo tamanho, um colegiado passa a tomar decisões inferiores em qualidade $^{15}$. De todo modo, o autor acredita que no contexto de democracias recentes,

[...] os tribunais menores devem estar associados a partidos políticos mais dominantes. Isso ocorre porque há menos facções preocupadas com a representação no tribunal e, portanto, menos necessidade de garantir o equilíbrio entre os membros. Além disso, cada juiz adicional aumenta o orçamento do tribunal, e há pouca razão para que um partido dominante deseje incorrer nesses custos extras, sendo outras coisas iguais. (tradução nossa) $)^{16}$.

Estudo empírico realizado por Tom Ginsburg concluiu que a média de número de juízes das recentes cortes constitucionais, criadas depois de 1989 (25 cortes), é de 11,25 magistrados, enquanto a média em cortes não especializadas que receberam também a competência de realizar revisão constitucional no mesmo período (5 cortes) é de 8,25 juízes. Pela interpretação do autor, os números indicam que "o exame de primeira

14 Ademais, o autor indica que há ampla evidência empírica apoiando a afirmação de que, em alguns contextos, a decisão colegiada é possui maior qualidade quando comparada a uma decisão individual. Cita o artigo de Stephen Bainbridge, "Why a Board? Goup Decision-making in Corporate Governance". BAINBRIDGE, Stephen M., Why a Board? Group Decisionmaking in Corporate Governance. Vanderbilt Law Review, Vol. 55, p. 01-55, 2002. Disponível em: $<$ https://ssrn.com/abstract=266683 $>$. Acesso em: 22 out 2017.

15 Ginsburg cita aqui os seguintes trabalhos: POSNER, Richard A.. Is the Ninth Circuit too Large?: A Statistical Study of Judicial Quality. The Journal Of Legal Studies, Chicago, v. 29, n. 2, p. 711-719, jun. 2000; e MUKHOPADHAYA, Kaushik. Jury Size and the Free Rider Problem. The Journal Of Law, Economics, And Organization, Oxford, v. 19, n. 1, p. 24-44, 2003.

16 No original: "[...] this is because there are less factions concerned with the representation on the court and hence less of a need for ensuring balance among the membership. Furthermore, each additional judge increases the budget of the court, and there is little reason a dominant party would want to incur these extra costs, other things being equal". Cf. GINSBURG, Tom. Judicial Review in New Democracies: Constitucional Courts in Asian Cases. Cambridge: Cambridge University Press, 2003, Kindle Edition, posição 547. 
instância das questões por parte dos tribunais de nível inferior economiza tempo mais tarde"17, quando da apreciação dos casos pelas cortes supremas, mesmo que elas tenham também casos não constitucionais para analisar.

In casu, trabalha-se com a hipótese de duas cortes constitucionais, o Supremo Tribunal Federal e a Corte Constitucional Colombiana, de modo que não se pode considerar a variável trazida por Ginsburg acerca do trabalho de cortes não especializadas. De todo modo, enquanto a corte brasileira é composta por 11 ministros ${ }^{18}$, integram o tribunal constitucional colombiano 9 magistrados ${ }^{19}$, número esse que não demonstra diferenças relevantes entre os órgãos estudados quanto ao fator "número de juízes".

\section{Mandato}

Enquanto no Brasil os Ministros possuem cargo vitalício com previsão de aposentadoria compulsória aos 75 anos de idade, a Constituição Política da Colômbia determina que cada juiz seja eleito para o período não renovável de oito anos.

Para Manuel José Cepeda-Espinosa ${ }^{20}$, o fato de os juízes da Corte Colombiana não poderem ser afastados do cargo nem ter seu termo renovado, permite uma atuação mais independente. Por outro lado, há quem defenda a proposição inversa, afirmando que quanto maior o tempo do mandato, maior também será a independência do magistrado, como afirma Ginsburg ${ }^{21}$.

A lógica por trás do pensamento de Ginsburg reside na ideia de que juízes que tenham a garantia de uma longa estadia em seu cargo não se veem compelidos a agir de acordo com as forças políticas dominantes, podendo empreender em decisões que tenham por objeto o bem comum, mesmo que obtido em longo prazo, em oposição a decisões imediatistas com o único escopo de realizar os interesses políticos vigentes. Ademais,

${ }_{17}$ GINSBURG, Tom. Judicial Review in New Democracies: Constitucional Courts in Asian Cases. Cambridge: Cambridge University Press, 2003, Kindle Edition, posição 551.

${ }^{18}$ Art. $101, \mathrm{CF} / 88$.

${ }^{19}$ Art. 44 da Lei 270 de 1996 - "Estatutaria de la Administración de Justicia"

${ }^{20}$ CEPEDA-ESPINOSA, M. J. Judicial Activism in a Violent Context: The Origin, Role, and Impact of the Colombian Constitutional Court. Washington University Global Studies Law Review, v. 3, n. 4, p. 529-700, 2004. p. 684.

${ }^{21}$ GINSBURG, Tom. Judicial Review in New Democracies: Constitucional Courts in Asian Cases. Cabridge: Cambridge University Press, 2003, Kindle Edition, posição 526. 
DESENHO INSTITUCIONAL E JUDICIALIZAÇÃO DA POLÍTICA NAS

CORTES CONSTITUCIONAIS BRASILEIRA E COLOMBIANA

o juiz que exerce seu cargo em um curto e determinado período provavelmente necessitará empregar-se novamente ao fim do mandato, de modo que preocupações com relação à tomada de decisões difíceis ou polêmicas podem afetar sua atuação na corte devido a preocupações com o futuro profissional.

Ginsburg defende ainda que cargos vitalícios não necessariamente representam mandatos mais longos que aqueles pré-determinados, isso porque a garantia da vitaliciedade geralmente vem acompanhada da determinação de aposentadoria compulsória, como é o caso do Brasil, que estabeleceu o limite de 75 anos.

Assim, cumpre investigar se o período de exercício do cargo de Ministros no STF, em geral, chega a ser menor ou maior que oito anos, como é determinado na Colômbia em relação aos juízes da Corte. O art. 101 da Constituição Federal estabeleceu a idade mínima de 35 anos para ocupação do cargo de Ministro do STF, assim, o mais longo mandato possível teria a duração de 40 anos, entretanto, dado o requisito constitucional de notável saber jurídico, geralmente juristas mais maduros são escolhidos para o cargo.

Dentre os atuais ministros do Supremo, aqueles que estão mais próximos da aposentadoria compulsória são Celso de Mello (71 anos), Marco Aurélio (71 anos), Ricardo Lewandovski (69 anos) e Rosa Weber (68 anos), os quais, considerando-se a data de sua nomeação e repelindo a hipótese de afastamento voluntário, permaneceriam no cargo por no máximo 31, 31, 17 e 12 anos, respectivamente. E em relação aos demais Ministros, Luiz Fux, Cármen Lúcia, Gilmar Mendes, Roberto Barroso, Dias Toffoli, Edson Fachin e Alexandre de Moraes, considerando-se as mesmas varáveis acima (idade ao ser nomeado $x$ data de atingimento dos 75 anos), teriam mandatos de no máximo 17, 23, 28, 20, 33, 18 e 26 anos, respectivamente. Assim, o mandato médio de um Ministro do STF seria de 23,27 anos, quase três vezes o mandato dos ministros da Suprema Corte Colombiana.

Se a impossibilidade de renovação do mandato garante uma maior independência aos juízes da Corte Colombiana, como afirma CepedaEspinosa, a vitaliciedade cumpre o mesmo papel no STF, e talvez de modo mais eficaz, pois os Ministros tem seu cargo garantido por mais tempo e até idade avançada, não havendo a preocupação com o futuro profissional e existindo uma maior liberdade para o envolvimento com decisões polêmicas e de cunho ativista.

\section{Mecanismos de escolha dos juízes}

Importante aspecto a ser analisado é o mecanismo de recrutamento dos magistrados das Cortes estudadas, fator que implica na maior ou menor independência política desses órgãos. Especialmente em teorias 
voluntaristas ${ }^{22}$ do ativismo judicial, é fundamental conhecer quem são e como foram selecionados aqueles juízes. A eleição dos juízes da Corte Constitucional Colombiana e do Supremo Tribunal Federal é bastante diferente, mesmo que em ambas a última palavra seja dada pelo Senado.

Anteriormente feita pelo método de cooptação de juízes pelos próprios membros da Corte, a eleição dos juízes da Corte Constitucional Colombiana, após a Constituição Política de 1991, passou a ser feita pelo Senado a partir de listas enviadas pelo Presidente da República, pela Corte Suprema e pelo Conselho de Estado, que indicam, cada, três potenciais candidatos $^{23}$. A casa legislativa realiza sessões privadas de apresentação de cada candidato, podendo formular questões pertinentes. Essa forma de seleção pretende equilibrar a pressão da escolha por parte do Presidente com a legitimidade dos órgãos representativos dos poderes de Estado, garantindo-se a prerrogativa de uma escolha da esfera política para um órgão politico.

No Brasil, a escolha do membros do Supremo Tribunal Federal é formalmente compartilhada entre os Poderes Executivo e Legislativo. O Presidente da República indica um candidato para compor o Supremo Tribunal Federal, entre brasileiros maiores de 35 anos, com notável saber jurídico e ilibada reputação, requisitos amplos e de avaliação subjetiva. Em um segundo momento, o candidato é submetido a uma sabatina pública pela Comissão de Constituição e Justiça do Senado Federal, devendo responder as perguntas dos Senadores. Uma vez aprovado o candidato pela comissão, seu nome é enviado para votação em plenário, exigindo-se quórum de maioria absoluta para aprovação ${ }^{24}$. A experiência demonstra, entretanto, que a sabatina pelo Senado é procedimento usualmente formal, não havendo real contestação das escolhas realizadas pelo Presidente, razão pela qual apenas cinco nomes foram rejeitados e nenhum deles sob a vigência da atual Constituição ${ }^{25}$.

\footnotetext{
${ }^{22}$ A tendência voluntarista de compreensão do ativismo judicial é bem representada sob a perspectiva de Barroso, para quem o ativismo judicial representa uma disposição do juiz para agir ativamente, diferentemente da judicialização, que é vista como decorrência da ampliação do sentido e alcance do texto constitucional. $C f$. BARROSO, Luis Roberto. Judicialização, Ativismo Judicial e Legitimidade Democrática. [Syn]Thesis, Rio de Janeiro, v. 5, n. 1, 2012, p. 28.

${ }^{23}$ Art. 239, Constituição Política de 1991.

${ }^{24}$ Art. 101, parágrafo único, CF/88 e arts. 101, II, i, e 288, III, d, do Regimento Interno do Senado Federal.

25 Todos foram rejeitados durante o governo de Floriano Peixoto (1891-1894): Barata Ribeiro, Inocêncio Galvão de Queiroz, Ewerton Quadros, Antônio Sève Navarro e Demosthenes da Silveira Lobo.
} 
DESENHO INSTITUCIONAL E JUDICIALIZAÇÃO DA POLÍTICA NAS CORTES CONSTITUCIONAIS BRASILEIRA E COLOMBIANA

Exceção à tal formalização talvez tenha sido a sabatina a que foi submetido o Ministro Edson Fachin. Indicado por Dilma Roussef quando já tinha uma base governista fragmentada, a sabatina, longe de pretender aferir o notável saber do candidato ou sua posição a respeito de temas candentes à sociedade brasileira, transformou-se em um debate entre situação e oposição, o que pouco questionava a competência jurídica do candidato. A exceção, nesse caso, serviu para afirmar a percepção de que a sabatina talvez seja um procedimento inadequado para a escolha dos ministros de cortes constitucionais.

O papel do Senado é destacado na Colômbia porque este não se limita apenas a aconselhar ou dar seu consentimento em relação ao candidato já escolhido pelo Presidente, como ocorre no Brasil. Pelo contrário, é o próprio órgão quem elege cada um dos nove juízes da Corte Constitucional, de modo que estes refletem a distribuição de forças políticas já existente no Senado e delineada pela escolha do povo quando das eleições. Cepeda-Espinosa exemplifica através da composição da Corte em 1992 quando foram eleitos "5 juízes de orientação liberal, dois independentes e dois conservadores", enquanto em 2000 a Corte era composta majoritariamente por juízes liberais.

No contexto brasileiro, por outro lado, não é possível sequer verificar a orientação ideológica dos Ministros do Supremo, seja pelo pluripartidarismo e dificuldade dicotômica entre liberais e conservadores, seja pela "ausência de uma cultura nacional favorável a concepções filosóficas mais rígidas e dogmáticas" 26 , como argumenta Marcelo Mazotti, em análise comparativa entre os Ministros do STF e da Suprema Corte estadunidense.

Alguns autores chegam a afirmar que "a legitimação popular do Senado é indiretamente transferida para os juízes da Corte Constitucional (Colombiana)". Para outros, o fato de parte dos juízes serem indicados pela Corte Suprema e pelo Conselho de Estado, órgãos jurídicos, torna a eleição mais legítima, pois "é de se supor que não agem com base em critérios políticos, como poderia fazer o Governo, mas estritamente técnico e jurídico, para escolher seus candidatos" 27 .

Pode-se concluir, assim, pela maior legitimidade do processo de escolha dos juízes da Corte Constitucional Colombiana em relação ao aplicável aos Ministros do Supremo. Se não chegarmos a tal conclusão

26 MAZOTTI, Marcelo. Jurisidção Constitucional e Ativismo Judiciário: análise comparativa entre a atuação do Supremo Tribunal Federal e da Suprema Corte estadunidense. 2012. 142 f. Dissertação (Mestrado) - Curso de Direito, Universidade de São Paulo, São Paulo, 2012, p. 95.

27 NARANJO MESA, Vladimiro. Diez Años de la Corte Constitucional Colombiana. Anuario Iberoamericano de Justicia Constitucional, Madrid, v. 5, p.277290, 2001, p. 279. 
pela simples constatação de que o mecanismo de eleição é diretamente realizado pelo Senado e, assim, reflete a vontade do povo, certo é que no país este órgão político é dotado de maior autonomia no processo decisório e, de fato, pode enfrentar decisões tomadas pelo Chefe do Executivo, o que não se pode dizer do caso brasileiro, no qual, usualmente, o Senado age timidamente e se conforma aos nomes indicados pelo Presidente.

\section{Acesso à Corte}

Para Ginsburg, o acesso à Corte é um elemento institucional que investiga principalmente dois aspectos: a escolha entre o sistema concentrado ou difuso de constitucionalidade, e os legitimados à propositura de uma ação perante o órgão constitucional ${ }^{28}$.

Como já referido, tanto no Brasil como na Colômbia, o papel do Poder Judiciário e especialmente do órgão superior de guarda da Constituição foi ressaltado pelas recentes Assembleias Constituintes. Tal fortalecimento se deu na Colômbia pela criação de uma Corte Constitucional, enquanto no Brasil houve a ampliação do rol de competências e instrumentos decisórios, assim como dos legitimados à propositura de demandas perante o STF.

No tocante à preferência pelo sistema de controle, ambas as jurisdições constitucionais estudadas fizeram a opção pelo sistema misto de controle de constitucionalidade. Entretanto, verificar-se-á que, enquanto o constituinte brasileiro de 1988 debruçou-se principalmente sobre o controle abstrato de normas, a Constituição Política de 1991 procurou também ampliar o controle concreto de constitucionalidade, pela criação da acción de tutela.

Desde a Constituição de 1981, adotou-se no Brasil o modelo difusoincidental de controle de constitucionalidade, tipicamente norteamericano. Por meio da ação direta genérica declaratória de inconstitucionalidade, instituída através da Emenda Constitucional $\mathrm{n}^{\mathrm{o}}$ 26/65 à Constituição de 1946, foi introduzido o controle abstrato de normas - mecanismo de controle, entretanto, que somente adquiriu maior relevância e abrangência após a Constituição de $1988^{29}$.

$\mathrm{Na}$ Constituição de 1988 foi reconhecida ao STF a competência originária para julgar variadas ações, aumentando-lhe o poder de

${ }_{28}$ GINSBURG, Tom. Judicial Review in New Democracies: Constitucional Courts in Asian Cases. Cabridge: Cambridge University Press, 2003, Kindle Edition, posição 417. 29 RAMOS, Elival da Silva. Ativismo Judicial: Parâmetros Dogmáticos. São Paulo: Saraiva, 2010, p. 276. 
DESENHO INSTITUCIONAL E JUDICIALIZAÇÃO DA POLÍTICA NAS CORTES CONSTITUCIONAIS BRASILEIRA E COLOMBIANA

decisão: (i) Ação Direta de Inconstitucionalidade (ADI), (ii) Ação Direta de Inconstitucionalidade por Omissão (ADO), (iii) Arguição de Descumprimento de Preceito Fundamental (ADPF), (iv) Mandado de Injunção, (v) Habeas Corpus (HC), (vi) Mandado de Segurança (MS) e Habeas Data (HD) ${ }^{30}$.

A ampliação do controle abstrato de constitucionalidade introduzida pela Constituição Federal foi complementada pelas Emendas 03/93 e 45/2004, além das Leis 9868/99 e 9882/99. A Emenda Constitucional noo 03 de 1993 foi responsável pela criação da Ação Declaratória de Constitucionalidade (ADC), como instrumento de fixação e homogeneização de entendimento diante de divergências interpretativas e jurisdicionais acerca do direito federal. Para Carlos Alexandre de Azevedo Campos ${ }^{31}$ “a ADC trouxe consigo a ampliação do poder interpretativo e decisório do Supremo em face, principalmente, das outras instâncias judiciais". As Leis no 9868/99 e no 9882/99, por sua vez, disciplinaram as ADI, ADC e ADPF. A ADPF, especialmente, foi prevista na Constituição de 1988 de maneira bastante genérica e dependia de regulamentação específica ${ }^{32}$, especialmente em virtude da ausência de antecedentes históricos ${ }^{33}$.

Em uma breve análise é possível perceber os esforços do constituinte originário e derivado, assim como do legislador infraconstitucional brasileiro, no sentido de otimizar o controle concentrado ou abstrato das normas, opção que encoraja a expansão da atividade judiciária e o incremento do controle judicial de constitucionalidade. Isso porque direitos socioeconômicos protegidos constitucionalmente apresentam-se, via de regra, em uma dimensão individual e outra coletiva. A primeira expressa-se nas ações individuais perante o Judiciário para a demanda de medicamentos, vaga na escola pública, condições dignas de trabalho, nas quais demanda-se ao judiciário para que determinado direito seja efetivado ao cidadão; já a dimensão coletiva transparece especialmente por meio de políticas públicas sobre direitos sociais (saúde, educação, trabalho, por exemplo), seja por demandas de grupos (direitos coletivos), seja por demandas que implicam em (re)definição de políticas (direitos difusos), e impactam nas opções (discricionárias) que o administrador

\footnotetext{
30 Todos previstos no art. 102, CF/88, com exceção do Mandado de Injunção, previsto no art. 5º, inciso LXXI.

31 CAMPOS, Carlos Alexandre de Azevedo. Dimensões do Ativismo Judicial do STF. Rio de Janeiro: Forense, 2014, p. 235.

32"a arguição de descumprimento de preceito fundamental, decorrente desta Constituição, será apreciada pelo Supremo Tribunal Federal na forma da lei".

${ }^{33}$ Razão pela qual Celso Bastos e Gilmar Ferreira Mendes chegaram a indagar se a ADPF "não teria o escopo de colmatar importantes lacunas identificadas no quadro de competências do Supremo Tribunal Federal".
} 
está obrigado a fazer, e que justamente implicam em seu programa de governo. São essas últimas demandas, justamente, as abarcadas pelo controle concentrado.

$\mathrm{Na}$ Colômbia, por outro lado, o modelo abstrato de constitucionalidade já existia desde a anterior constituição de 1886, e foi ampliado pelo Ato $\mathrm{n}^{-} 3$ de 1910, que criou a actio popularis, também chamada acción pública, através da qual qualquer cidadão pode ajuizar uma demanda de declaração de inconstitucionalidade de lei federal perante a Corte Suprema, à época responsável pelo controle de constitucionalidade. A Constituição de 1991 entretanto, ampliou esse controle em dois importantes aspectos: quanto ao rol de normas submetidas ao controle ex officio pela Corte Constitucional e ao âmbito de aplicação da actio popularis já existente.

Se antes os juízes da corte deveriam revisar de ofício apenas os decretos presidenciais emitidos em qualquer situação de estado de exceção, a partir da Constituição de 1991, as hipóteses de atos e decisões que devem passar pelo crivo da Corte aumentaram exponencialmente: leis de aprovação de tratados internacionais, assim como os tratados em si; statutory laws ${ }^{34}$, antes de assinadas pelo presidente; atos de convocação de Assembleia Constituinte ou referendo para modificar a constituição, acerca de sua validade formal; e qualquer mecanismo de participação popular - referendo, plebiscito ou consulta popular - de ordem nacional.

No que diz respeito às actio popularis, ações que podem ser propostas por qualquer cidadão contra leis, emendas constitucionais (no que tange a sua validade formal) e decretos presidenciais, assim como tratados internacionais internalizados antes da promulgação da Constituição de 1991, passaram a ser apresentadas perante a Corte sem a formalidade de representação através de advogado e também sem a necessária demonstração de interesse legal na matéria impugnada.

Além do requerente, passaram a poder intervir na avença judicial qualquer cidadão, o Procurador Geral da República ${ }^{35}$ e as autoridades responsáveis pela edição da norma sujeita ao controle de

34 Outra inovação da Constituição de 1991, em seu artigo 152, são as leis estatutárias, mediante as quais o Congresso regulará cinco matérias específicas de conteúdo político: i) direitos e deveres fundamentais e mecanismos para sua proteção, ii) administração da justiça, iii) organização e regime dos partidos políticos, iv) instituições e mecanismos de participação popular, v) estabelecimento de estado de exceção. $\mathrm{O}$ trâmite dessa leis também exige um procedimento todo especial, pela maioria absoluta do Congresso e completar-se em uma única legislatura, ademais da revisão prévia do projeto pela Corte Constitucional (artigos 153 e 242 da Constituição).

35 Procurador General de la Nación. 
DESENHO INSTITUCIONAL E JUDICIALIZAÇÃO DA POLÍTICA NAS CORTES CONSTITUCIONAIS BRASILEIRA E COLOMBIANA

constitucionalidade. A Constituição Política de 1991 também foi responsável por limitar o tempo de tramitação da actio popularis ${ }^{36}$, "o que vem resultando em um número muito maior de decisões de controle abstrato pela Corte Constitucional do que havia sob a jurisdição da Suprema Corte" 37 .

Para Elival da Silva Ramos, a principal razão pela qual a expansão do controle abstrato de normas importa no desenvolvimento da judicialização da política "está na maior proximidade do controle de constitucionalidade, assim efetuado (pelo controle abstrato), do exercício da função legislativa, ainda que se trate (...) do exercício da função jurisdicional" 38 .

O controle abstrato de normas incentiva a atividade criativa do julgador também pelo caráter das normas que utiliza como parâmetro de verificação da constitucionalidade. Para fiscalizar a validade de uma norma em abstrato, geralmente são utilizadas regras constitucionais de conteúdo indeterminado e normas principiológicas, as quais garantem ao juiz uma maior liberdade de ação hermenêutico-concretizadora.

No mesmo sentido é a lição de Mauro Cappelletti ${ }^{39}$ quando afirma que "independentemente da eventual inserção dos direitos sociais nas constituições, os textos constitucionais e, em seu âmbito, os catálogos dos direitos fundamentais, são normalmente redigidos de forma mais breve e sintética" o que implica, inevitavelmente, ao tribunal investido na tarefa precípua de realizar e garantir a supremacia da constituição o "dilema de dar conteúdo a tais enigmáticos e vagos preceitos, conceitos e valores (tarefa, claro esta, altamente criativa)".

Ademais, o fomento do ativismo judicial pela ampliação dos mecanismos de controle de constitucionalidade, especialmente em sede de controle abstrato ou concentrado, é uma tendência verificada em tribunais recentemente estabelecidos ou em tribunais consagrados que passem a exercer mais intensamente esse tipo de controle, como é o caso da Corte Constitucional Colombiana e do Supremo Tribunal Federal, respectivamente. Para Elival da Silva Ramos, "apenas o amadurecimento institucional, e o self-restraint que sempre o acompanha, fornece o

\footnotetext{
${ }^{36}$ Art. 242 da Constituição Política de 1991

${ }^{37}$ CEPEDA-ESPINOSA, M. J. Judicial Activism in a Violent Context: The Origin, Role, and Impact of the Colombian Constitutional Court. Washington University Global Studies Law Review, v. 3, n. 4, p. 529-700, 2004, p. 556: “The new structure limits procedural delays, which is resulting in a much higher number of abstract review decisions by the Constitutional Court than there was under the Supreme Court."

38 RAMOS, Elival da Silva. Ativismo Judicial: Parâmetros Dogmáticos. São Paulo: Saraiva, 2010, p. 277.

39 CAPPELLETTI, Mauro. Juízes Legisladores? Porto Alegre: Sergio Antonio Fabris Editor, 1993. 134 p. Tradução de Carlos Alberto Alvaro de Oliveira. p. 67-68.
} 
antídoto a esse fator de impulsão do ativismo judicial, como sucedeu no sistema de controle europeu" ${ }^{\prime 4}$.

O principal mérito do constituinte colombiano de 1991, entretanto, foi ter criado a acción de tutela, em sede de controle concreto de constitucionalidade, ação que permite aos cidadãos requerer a qualquer juiz, com competência territorial, que este profira decisão protegendo seus direitos fundamentais quando estes estão sendo ameaçados ou violados, e o magistrado, por sua vez, terá que decidir a avença em dez dias, motivo pelo qual o instrumento é visto como a mais efetiva garantia de direitos fundamentais para o cidadão ${ }^{41}$.

As acciones de tutela são ajuizadas perante qualquer juiz, porém, todas as suas decisões devem passar pelo crivo da Corte Constitucional para uma possível revisão, aumentando muito a demanda perante o tribunal. Vladimiro Naranjo Mesa ${ }^{42}$ reforça a noção de não se tratar a revisão das decisões pela Corte de uma instância processual, mas de revisão eventual com o objetivo básico de assentar uma jurisprudência em casos paradigmáticos e dessa forma ajudar os demais juízes em casos análogos. A revisão cumpre a função ainda de unificação da jurisprudência e é decisiva para a obtenção de um pronunciamento da corte em casos de repercussão nacional.

Enquanto na Colômbia parece existir uma peocupação com a uniformização do entendimento da Corte em situações que envolvam dieitos fundamentais, o mesmo não ocorre no Brasil. A extensão do controle da constitucionalidade do Supremo Tribunal Federal não é comparável a outras cortes no mundo, e seu gigantismo infelizmente não traduz uma preocupação com a segurança jurídica ou com a uniformaização da jurisprudência. De fato, o Supremo Tribunal Federal, como assevera Claudia Barbosa, "acumula no Brasil uma dupla função: atua como corte constitucional e órgão de cúpula do Poder Judiciário

40 RAMOS, Elival da Silva. Ativismo Judicial: Parâmetros Dogmáticos. São Paulo: Saraiva, 2010, p. 730.

${ }^{41}$ NARANJO MESA, Vladimiro. Diez Años de la Corte Constitucional Colombiana. Anuario Iberoamericano de Justicia Constitucional, Madrid, v. 5, 2001, p. 285.

42 NARANJO MESA, Vladimiro. Diez Años de la Corte Constitucional Colombiana. Anuario Iberoamericano de Justicia Constitucional, Madrid, v. 5, p.277290, 2001, p. 285. 
DESENHO INSTITUCIONAL E JUDICIALIZAÇÃO DA POLÍTICA NAS CORTES CONSTITUCIONAIS BRASILEIRA E COLOMBIANA

brasileiro. É ao mesmo tempo órgão político e órgão judiciário" 43 e sua competência para estabelecer a revisão judicial é praticamente absoluta.

Manuel José Cepeda-Espinosa afirma que na década entre 1992 e 2002, o controle abstrato de constitucionalidade representou $32 \%$ do total final de decisões proferidas pela Corte Colombiana, enquanto o controle concreto através da revisão das acciones de tutela representou $68 \%$ de toda a demanda.

Pelo exposto, percebe-se que enquanto no Brasil a Constituição de 1988 foi responsável por reforçar o controle abstrato de normas, o constituinte colombiano foi além, e não obstante ter ampliado o controle abstrato, impulsionou a expansão do Poder Judiciário também pela criação das acciones de tutela, em sede de controle concreto, o que se deve, possivelmente, ao fato de que o controle abstrato de normas já existia e estava consolidado no país desde 1910.

Isso não significa que a Constituição de 1991 não conferiu importância ao controle abstrato de normas, pelo contrário, Manuel José CepedaEspinosa, em minucioso estudo sobre a Corte Constitucional Colombiana, ressalta que entre 1992 e 2002 o número de decisões concernentes ao controle abstrato de constitucionalidade aumentou em $639 \%$, o que se deve, segundo o autor, principalmente à crescente quantidade de actio popularis ajuizadas, após as facilidades e melhorias aplicadas pela Constituição Política de 1991.

Pela tradição de quase oito décadas realizando o controle abstrato de normas, através da Suprema Corte, quando a Corte Constitucional Colombiana começou a funcionar, em 1992, a cultura jurídica e a sociedade colombiana já estava acostumada com o tipo de revisão judicial de normas, de modo que a Corte, apesar de ser uma instituição nova, já possuía aceitação no meio jurídico e político, o que facilitou a sua consolidação e o desenvolvimento de uma postura ativista pelos seus juízes ${ }^{44}$.

Assim, verifica-se a relevância do controle abstrato de normas em ambos os sistemas constitucionais estudados como forma de impulsionamento da judicialização da política, e, no sistema colombiano, a importância do controle concreto para a atividade da Corte Constitucional, controle este que, se não impulsiona a judicialização da política pela atividade criativa do juiz, uma vez que o instrumento, no âmbito da Corte, serve muito mais à uniformização, a reforça no que

43 BARBOSA, Claudia Maria. O Supremo Tribunal Federal e as Condições de Indpendência do Poder Judiciário Brasileiro. Revista da Academica Brasileira de Direito Constitucional. Curitiba, v. 4, p. 41-63, 2003.

${ }^{44}$ UPRIMNY YEPES, Rodrigo. A JUDICIALIZAÇÃO DA POLÍTICA NA COLÔMBIA: CASOS, POTENCIALIDADES E RISCOS. Sur - Revista Internacional de Direitos Humanos, v. 6, 2007, p. 65. 
tange ao segundo tópico de análise no elemento acesso à corte, qual seja a maior ou menor limitação dos legitimados à propositura de ação perante a Corte Constitucional.

Na Colômbia, como visto, os cidadãos, seja pela actio popularis, seja pela acción de tutela, tem amplo acesso à Corte. No Brasil, em contrapartida, esse acesso é restrito a autoridades e órgãos de larga representação nacional ${ }^{45}$. Embora a legitimidade ativa para ingressar com ações constitucionais tenha se ampliado no Brasil com a Constituição de 88, ela é ainda bastante tímida, quando comparado aos mecanismos de aceso à Corte colombiana. No Brasil ampliou-se o rol de instituições que, por seus representantes, estão aptas a questionar a constitucionalidade de uma norma; na Colômbia enfatizou-se a capacidade do cidadão de aceder ao Judiciário para exigir do Estado o respeito e a efetivação dos direitos constitucionalmente estabelecidos.

De fato, comparativamente, apesar da expansão prevista no artigo 103 da $\mathrm{CF} / 88$, que atribuiu legitimidade ativa a diferentes órgãos da sociedade, o espaço atribuído ao cidadão foi muito acanhado, de maneira que o controle abstrato resta ainda concentrado em instituições que agem, via de regra, de maneira corporativa, afastando o cidadão do exercício de sua cidadania ativa ${ }^{46}$.

Assim é que, a despeito da criação de novos mecanismos de controle de constitucionalidade perante o STF, a principal mudança trazida pela $\mathrm{CF} / 88$ foi a ampliação da legitimidade ativa para a propositura da ADI, permitindo, como ressalta Gilmar Ferreira Mendes" ${ }^{47}$, que "praticamente todas as controvérsias constitucionais relevantes sejam submetidas ao

${ }_{45}$ CAMPOS, Carlos Alexandre de Azevedo. Dimensões do Ativismo Judicial do STF. Rio de Janeiro: Forense, 2014, p. 233.

${ }^{46} \mathrm{O}$ artigo 103 da CF/88 estabelece: "Art. 103. Podem propor a ação direta de inconstitucionalidade e a ação declaratória de constitucionalidade:

I - o Presidente da República;

II - a Mesa do Senado Federal;

III - a Mesa da Câmara dos Deputados;

IV - a Mesa de Assembléia Legislativa ou da Câmara Legislativa do Distrito Federal;

V - o Governador de Estado ou do Distrito Federal;

VI - o Procurador-Geral da República;

VII - o Conselho Federal da Ordem dos Advogados do Brasil;

VIII - partido político com representação no Congresso Nacional;

IX - confederação sindical ou entidade de classe de âmbito nacional."

47 MENDES, Gilmar Ferreira; BRANCO, Paulo Gustavo Gonet. Curso de Direito

Constitucional. 9. ed. São Paulo: Saraiva, 2014. p. 1076. 
DESENHO INSTITUCIONAL E JUDICIALIZAÇÃO DA POLÍTICA NAS CORTES CONSTITUCIONAIS BRASILEIRA E COLOMBIANA

Supremo Tribunal Federal mediante processo de controle abstrato de normas".

Para Ginsburg, a legitimação para propositura de ação perante a Corte é o mais importante fator para a expansão do Poder Judiciário, pois o amplo acesso à Corte descentraliza a deflagração do controle de constitucionalidade e aumenta a possibilidade de atores políticos serem questionados perante a Corte quando falharem ao cumprir os preceitos constitucionais a que estão submetidos ${ }^{48}$.

Ademais, segundo o autor, a escolha pela ampliação ou limitação do acesso à Corte guarda relação com a perspectiva de distribuição das forças políticas no futuro, pois o "explícito poder constitucional e acesso ao controle de constitucionalidade serão maiores onde as forças políticas forem difusas do que onde existe um único partido político dominante" ${ }^{49}$ Assim, em um arranjo onde não há um só partido político dominante, as forças políticas conflitantes vão procurar maximizar o acesso à jurisdição constitucional pelas minorias legislativas e cidadãos comuns como forma de assegurar a lisura do processo eleitoral e a possibilidade democrática de novo acesso ao poder em caso de perda neste: "nós devemos assim esperar uma correlação entre incerteza política e amplo acesso [à Corte Constitucional]". ${ }^{50}$

Carlos Alexandre de Azevedo Campos corrobora com a teoria de Ginsburg ao explicar o avanço do ativismo judicial do Supremo Tribunal Federal após a redemocratização, afirmando que a fragmentação horizontal e a "difusão do poder político pode favorecer a ascensão institucional das cortes em dois aspectos - (i) eleva as oportunidades de conflitos e, consequentemente, de judicialização de questões políticas relevantes; (ii) aumenta a independência das cortes para decidir sobre essas questões, haja vista a inexistência de uma instância hegemônica de poder $^{\prime \prime} 51$.

${ }^{48}$ GINSBURG, Tom. Judicial Review in New Democracies: Constitucional Courts in Asian Cases. Cabridge: Cambridge University Press, 2003, Kindle Edition, posição 425.

${ }^{49}$ No original: "Explicit constitutional power of and access to judicial review will be greater where political forces are diffused than where a single dominant party exists at the time of constitutional design"; Cf. GINSBURG, Tom. Judicial Review in New Democracies: Constitucional Courts in Asian Cases. Cabridge: Cambridge University Press, 2003, Kindle Edition, posição 274.

${ }^{50}$ No original: "We should thus expect a correlation between political uncertainty and open access"; Cf. GINSBURG, Tom. Judicial Review in New Democracies: Constitucional Courts in Asian Cases. Cabridge: Cambridge University Press, 2003, Kindle Edition, posição 433.

${ }^{51}$ CAMPOS, Carlos Alexandre de Azevedo. Dimensões do Ativismo Judicial do STF. Rio de Janeiro: Forense, 2014, p. 214. 
Colômbia e Brasil ampliaram as formas de acesso às cortes constitucionais. Contudo, enquanto a Colômbia privilegiou o cidadão, o Brasil optou por fortalecer a acesso institucional às cortes. De fato, na Colômbia o acesso foi facilitado por meio das acciones de tutela e das facilidades implementadas ao ajuizamento das actio popularis; no Brasil, ao contrário, o ajuizamento das ações visando controle de constitucionalidade foi conferido ao Conselho Federal da Ordem dos Advogados do Brasil, a partidos políticos com representação no Congresso Nacional e confederações sindicais ou entidades de classe de âmbito nacional, órgãos que podem eventualmente representar a vontade de minorias não contempladas pela atividade política majoritária, mas via de regra não alcançam o cidadão.

\section{Efeitos das decisões}

A análise dos efeitos das decisões é cara ao debate da judicialização da política porque diz sobre o maior ou menor poder das cortes constitucionais de intervenção na vida social. Para Carlos Alexandre de Azevedo Campos, "quanto mais abrangentes e vinculantes forem os efeitos das decisões, mais poder a corte exercerá sobre os demais atores e sobre a própria sociedade ${ }^{\prime \prime 52}$. Cabe, aqui, então, analisar quem é atingido e qual grau de obediência devido às decisões do STF e da Corte Constitucional Colombiana.

Em geral, assim como acontece no Brasil, a Corte Constitucional Colombiana adota dois tipos de decisão, ou seja, julgamentos em controle abstrato e em controle concreto de constitucionalidade, com efeitos erga omnes no primeiro tipo e inter partes no segundo. No caso do controle abstrato, no Brasil, a eficácia das decisões proferidas em ADC e ADI tem ainda efeito vinculante, ou seja, obriga também os demais órgãos do Poder Judiciário e a administração pública direta e indireta, nas esferas municipal, estadual e federal ${ }^{53}$.

Na Colômbia, o art. 243 da Constituição Política de 1991 determina que todas as autoridades devem obediência às decisões proferidas em sede de controle de instrumento legal caracterizado inconstitucional em decisões de mérito. Entretanto, a divisão dos efeitos das decisões trazida acima não é de fato tão simplista e ambas as cortes desenvolveram um complexo sistema de possibilidades de efeitos que essas decisões podem ter. Trata-se da modulação dos efeitos decisórios.

52 CAMPOS, Carlos Alexandre de Azevedo. Dimensões do Ativismo Judicial do STF. Rio de Janeiro: Forense, 2014, p. 214.

${ }^{53}$ Art. 102, § 2⿳⺈, CF/88. 


\title{
DESENHO INSTITUCIONAL E JUDICIALIZAÇÃO DA POLÍTICA NAS
}

\author{
CORTES CONSTITUCIONAIS BRASILEIRA E COLOMBIANA
}

Elival da Silva Ramos, por sua vez, destaca a modulação temporal dos efeitos da decisão e a modulação do conteúdo normativo do ato objeto do controle de constitucionalidade como principais temas a serem investigados quando da análise da aproximação da atividade judicante com a legislativa, quando do estudo do ativismo judicial.

Tradicionalmente, no Brasil, foi regra a nulidade absoluta do ato normativo declarado inconstitucional, com efeitos ex tunc, preservandose apenas as situações concretas já constituídas com amparo na norma invalidada, sob a justificativa da manutenção da segurança jurídica do ordenamento. A situação mudou com o advento do art. 27 da lei 9868/99, responsável por estabelecer a possibilidade de modulação temporal dos efeitos das decisões de mérito em ADC e ADI, assim como o fez o art. 11, da Lei 9882/99 com relação à ADPF.

Com base nos enunciados normativos, o STF, por razões de segurança jurídica ou de excepcional interesse social, analisados no caso concreto, pode restringir os efeitos ou decidir que eles tenham eficácia prospectiva, ou seja, a partir do trânsito e julgado da decisão, ou a partir de outro momento que venha a ser fixado, realizando a modulação temporal dos efeitos da decisão (efeitos futuros ou retroativos), desde que respeitada a maioria de dois terços dos votos dos membros do tribunal.

Na Corte Constitucional Colombiana, o assunto não é muito diferente, a não ser pelo fato de que a variedade de possíveis efeitos da decisão é fruto de construção jurisprudencial do próprio tribunal. O Decreto 2067 de 1991, em seu artigo 21 limitava os casos nos quais os efeitos das decisões proferidas em controle abstrato de constitucionalidade poderiam ter efeitos retroativos, levando a Corte a proferir decisão ${ }^{54}$ afirmando sua autonomia para determinar os efeitos de suas decisões, os quais encontrariam limites apenas no texto e no espírito da Constituição.

Assim, a modulação dos efeitos temporais das decisões da Corte Constitucional Colombiana superou a regra geral de efeitos pro futuro, ou seja, a partir do trânsito em julgado e obrigatoriedade de aplicação da decisão, permitindo aos juízes decidir, sem qualquer procedimento especial (como existem requisitos no Brasil), pela aplicação retroativa ou futuro dos efeitos das suas decisões.

Quanto à restrição dos efeitos da decisão, o enunciado inovador do art. 27 da Lei 9868/99 permite à Corte a adoção de medidas que não somente declarem a nulidade total do texto legal, mas a declaração de nulidade parcial, a declaração de inconstitucionalidade sem redução de texto - em que a corte declara inconstitucional uma ou mais hipóteses de aplicação da lei -, e a interpretação conforme a constituição, em que a corte preserva o enunciado desde que interpretado de maneira

${ }^{54}$ COLÔMBIA. Corte Constitucional. Sentencia C-113/93, de 25/03/1993. 
compatível com a constituição, excluindo a interpretação que a ela seja contrária.

Seguindo a mesma tendência de flexibilização, a Corte Constitucional Colombiana também pratica a modulação de efeitos das decisões em relação ao conteúdo da lei declarada inconstitucional, proferindo decisões interpretativas, expressamente integrativas e materialmente expansivas $^{55}$.

As decisões modulativas interpretativas podem determinar: (i) o exato significado/interpretação a ser conferido ao texto legal, (ii) a restrição da aplicação da lei, excluindo hipóteses de aplicação (julgamentos redutivos), (iii) a incorporação de requisitos a serem observados quando da aplicação da norma para que esta se torne válida.

Em decisões expressamente integrativas a Corte Constitucional Colombiana declara que houve uma omissão legislativa em relação à abrangência da lei revisada e amplia, na própria decisão, a área de efetividade do instrumento legal, aplicando-o diretamente aos sujeitos e circunstâncias que entender necessárias de acordo com a Constituição.

Por fim, as decisões materialmente expansivas, conforme explica Cepeda-Espinosa "compreendem todos os diferentes tipos de decisões que não se encaixam nas categorias, mas que a Corte vem adotando desde 1992", uma vez que ela "tem consistentemente afirmado seu poder exclusivo de determinar os efeitos das próprias decisões, tanto em julgamentos de controle concreto como abstrato, como parte de sua missão genérica de guardar a supremacia e integridade da Constituição" 56 .

Para Elival da Silva Ramos, há maior liberdade decisória no tribunal quando as regras sobre a modulação dos efeitos não advém do legislador, mas sim de construção da própria corte: "por vezes desfrutará o juiz constitucional de maior liberdade, como sucede nos sistemas que acolhem a anulabilidade, porém, não regulam, na Constituição ou na legislação subalterna, a projeção de efeitos temporais quanto aos atos

${ }^{55}$ CEPEDA-ESPINOSA, M. J. Judicial Activism in a Violent Context: The Origin, Role, and Impact of the Colombian Constitutional Court. Washington University Global Studies Law Review, v. 3, n. 4, 2004, p. 566.

${ }^{56}$ No original: "In this sense, one must recall that the Court has consistently affirmed its exclusive power to determine the effects of its own decisions, in both abstract and concrete review judgments, as part of its generic mission to guard the supremacy and integrity of the Constitution"; Cf. CEPEDA-ESPINOSA, M. J. Judicial Activism in a Violent Context: The Origin, Role, and Impact of the Colombian Constitutional Court. Washington University Global Studies Law Review, v. 3, n. 4, 2004, p. 564. 
DESENHO INSTITUCIONAL E JUDICIALIZAÇÃO DA POLÍTICA NAS CORTES CONSTITUCIONAIS BRASILEIRA E COLOMBIANA

sancionados" ${ }^{\prime 57}$. Enquanto nos casos em que há previsão explícita da possibilidade de modulação, o juiz inicialmente estaria agindo em sintonia com o ordenamento jurídico, não se tratando de ativismo judicial.

\section{CONCLUSÃO}

O fenômeno de judicialização da política provoca diversos questionamentos, especialmente no que concerne à legitimidade democrática e capacidade institucional do Poder Judiciário para a tomada de suas decisões. Não obstante, como visto, a judicialização da política é uma realidade, razão pela qual o presente artigo partiu de uma perspectiva fenomenológica, tomando-se como premissa a existência da judicialização da política tanto na jurisdição brasileira, como na colombiana.

Permitiu-se, assim, partir diretamente à análise da conformação da judicialização da política com o ordenamento jurídico-constitucional vigente em cada um dos dois Estados estudados, verificando-se de que forma as prescrições institucionais trazidas pelo direito vigente, após a promulgação da Constituição Federal de 1988 e da Constituição Política de 1991, importaram ao desenvolvimento da judicialização da política em cada país.

Assim é que foram estabelecidos critérios analíticos de comparação institucional dos órgãos supremos de controle constitucional brasileiro e colombiano, procurando-se extrair do sopesamento das características de cada ordenamento, conclusões acerca de uma atuação mais ou menos política e ativista em cada órgão. Para tanto, foram analisados o número, mandato e mecanismo de escolha dos juízes do STF e da Corte Constitucional Colombiana e, ainda, o acesso às cortes e os efeitos das suas decisões.

Os três primeiros critérios dizem sobre a maior ou menor independência dos juízes no desempenho de sua atividade de guardiões do conteúdo e da supremacia constitucional. Em relação ao número de juízes, adotando-se a interpretação de Tom Ginsburg e considerando-se que todas as demais variáveis sejam iguais entre as cortes, pode-se dizer que quanto mais componentes, mais lento e oneroso o processo decisório, porém também mais confiável. No Brasil e na Colômbia, a quantidade de magistrados integrantes da corte constitucional não difere muito, sendo 11 Ministros na primeira e 9 juízes na segunda, adequando-se à média encontrada por Tom Ginsburg para as cortes especializadas criadas ou fortalecidas recentemente (depois de 1989).

57 RAMOS, Elival da Silva. Ativismo Judicial: Parâmetros Dogmáticos. São Paulo: Saraiva, 2010, p. 202. 
No que tange ao mandato dos magistrados, as características de cada corte são mais discrepantes. Enquanto os Ministros do STF possuem cargo vitalício e aposentadoria compulsória aos 75 anos, os juízes da Corte Constitucional Colombiana são eleitos para o período não renovável de oito anos. Isolando-se esse fator de outras variáveis (como as experiências pessoais e profissionais dos juízes, o papel da mídia e a transmissão dos julgamentos, por exemplo), concluiu-se que quanto mais longo e seguro for o mandato, maior a probabilidade de o juiz exercer seu ofício de maneira independente, razão pela qual o modelo institucional adotado no Brasil seria mais propício ao desenvolvimento da judicialização da política.

O mecanismo de escolha dos juízes é outro fator diferenciador. Apesar de em ambos os países o processo de escolha terminar com a aprovação ou reprovação pelo Senado, no Brasil a sabatina do nome indicado pelo Presidente é considerada mera formalidade, enquanto na Colômbia é o Senado quem realmente faz a escolha, a partir de listas enviadas pelo Chefe do Executivo, pelo Conselho de Estado e pela Corte Suprema.

Assim, os magistrados nomeados para a Corte Constitucional Colombiana possuem maior legitimidade democrática porque escolhidos pelos representantes diretos da vontade popular - os membros do Senado - reproduzindo no tribunal a pluralidade de orientações políticas reveladas naquela casa do Congresso. Isso mitigaria uma das principais críticas à judicialização da política - o déficit democrático - naquele país.

Os fatores de acesso às cortes e efeitos de suas decisões, por sua vez, dizem sobre o maior ou menor poder decisório da corte. Quanto ao primeiro deles, foi ampliado no Brasil pela possibilidade de ajuizamento das ações constitucionais pelos legitimados do art. 103 da Constituição de 1988, destacando-se por conferir o acesso não só a autoridades, como confederações sindicais ou entidades de classe (de âmbito nacional). Já na Colômbia, a previsão é mais ampla, permitindo que mesmo cidadãos sem específico interesse na causa possam ajuizar pleitos perante a Corte Constitucional para assegurar a supremacia da constituição, possibilitando que uma agenda mais ampla de questões políticas e sociais seja judicializada.

Sobre os efeitos das decisões, de regra, ambas as cortes adotam efeito inter partes no controle difuso e erga omnes e vinculante no controle abstrato - o que vem sendo flexibilizado. No Brasil, foram os artigos 27 da Lei 9868/99 e 11 da Lei 9882/99 que permitiram, por razões de segurança jurídica ou excepcional interesse social, a modulação dos efeitos da decisão de inconstitucionalidade, tanto em relação ao tempo em que os efeitos seriam aplicados, como ao conteúdo da lei controlada que seria declarado inconstitucional. Na Colômbia, por outro lado, a 
DESENHO INSTITUCIONAL E JUDICIALIZAÇÃO DA POLÍTICA NAS

CORTES CONSTITUCIONAIS BRASILEIRA E COLOMBIANA

excecionalidade à regra adveio de construção jurisprudencial da própria corte, demonstrando sua independência criativa em relação aos ditames do direito vigente.

Ante o exposto, não causa espanto o fato de a Corte Constitucional Colombiana ser considerada uma das mais ativistas do mundo. A não ser pelo mandato fixo e não renovável, todos os outros fatores analisados demonstram uma maior independência de seus juízes e um poder decisório mais amplo, quando comparada à realidade brasileira. Outrossim, a atuação da corte colombiana parece mais legítima porque permeada pela vontade popular, seja indiretamente na escolha de juízes, seja pelo ajuizamento direto de ações, o que autorizaria mais facilmente um controle judicial das políticas públicas, tradicionalmente deixadas ao crivo do Legislativo e Executivo.

O ativismo, contudo, não deve ser apenas comemorado, já que não é bom ou mal em si mesmo. Ele indica um desequilíbrio entre os Poderes e traduz uma expectativa em relação à realização de direitos que, de fato, deveria ser cobrada do Legislativo e do Executivo. O risco do ativismo aumenta quando não existe o freio eficaz que o contenha, tornando o Poder Judiciário por vezes imune à responsabilidade que se exige de todo Poder republicano em um Estado Democrático de Direito. Nesse sentido a análise institucional realizada no presente artigo é bastante útil, na medida em que torna claro o quanto a arquitetura das instituições analisadas influenciam no comportamento das cortes, tanto em relação ao cidadão, quanto com respeito aos demais Poderes e instituições.

É importante ponderar, não obstante, que as conclusões aqui obtidas com base nos fatores de comparação estabelecidos por Ginsburg e sua relação com a maior ou menor independência e poder decisório das cortes constitucionais não devem ser entendidas de forma peremptória ou isolada de suas premissas, tendo em vista que na prática a atuação das cortes é influenciada por diversos outros fatores aqui não considerados, como, por exemplo, o contexto sociopolítico do país, a experiência pessoal e profissional de seus membros e a publicização ou não do processo de tomada de decisão.

\section{REFERÊNCIAS}

ROSA, Brunna. Assassinato de Sindicalista Leva para 30 as Mortes de Líderes Políticos na Colômbia. Federação dos trabalhadores em empresas de crédito do Paraná, 2008. Disponível em: $<$ http://www.fetecpr.org.br/assassinato-de-sindicalista-leva-para-30-asmortes-de-lideres-politicos-na-colombia> . Acesso em: 17 jan. 2017. 
Bainbridge, Stephen M., Why a Board? Group Decisionmaking in Corporate Governance. Vanderbilt Law Review, Vol. 55, pp. 1-55, 2002. Disponível em: $<$ https://ssrn.com/abstract=266683. Acesso em: 22 out. 2017.

BARBOSA, Claudia Maria. O Supremo Tribunal Federal e as Condições de Indpendência do Poder Judiciário Brasileiro. Revista da Academica Brasileira de Direito Constitucional. Curitiba, v. 4, p. 41-63, 2003.

BARBOZA, Estefânia Maria de Queiroz; KOZICKI, Katya. Judicialização da política e controle judicial de políticas públicas. Rev. Direito GV, São Paulo, v. 8, n. 1, p. 59-85, 2012. Disponível em <http://www.scielo.br/scielo.php?script=sci arttext\&pid=S180824322012000100003\&lng=en\&nrm=iso>. Acesso em: 17 jan. 2017.

BARROSO, Luis Roberto. Judicialização, Ativismo Judicial e Legitimidade Democrática. [Syn]Thesis, Rio de Janeiro, v. 5, n. 1, p. 2332, 2012.

BERNAL, Carlos. Unconstitutional Constitutional Amendments in the Case Study of Colombia: an analysis of the justification and meaning of the constitutional replacement doctrine. International Journal of Constitutional Law, New York, v. 11, p. 339-357, 2013.

BITENCOURT NETO, Eurico. Vinculação da Administração Pública ao Mínimo Existencial. In: NETTO, Luísa Cristina Pinto; BITENCOURT NETO, Eurico. (Org.). Direito Administrativo e Direitos Fundamentais: diálogos necessários. Belo Horizonte: Fórum, 2012, p. 153-174.

BRANDÃO, R. A Judicialização da Política: teorias , condições e o caso brasileiro. Revista de Direito Administrativo, v. 263, p. 175-220, 2013. 
DESENHO INSTITUCIONAL E JUDICIALIZAÇÃO DA POLÍTICA NAS CORTES CONSTITUCIONAIS BRASILEIRA E COLOMBIANA

BRASIL. Constituição (1988). Constituição da República Federativa do Brasil de 1988. Brasília, 1988.

Senado Federal. Regimento Interno, versão consolidada pela Secretaria-Geral da Mesa do Senado Federal e publicada no Suplemento do Diário do Senado Federal em 02.02.2015. Disponível em: $<$ https://www25.senado.leg.br/documents/12427/45868/RISFCompilado. pdf/cd5769c8-46c5-4c8a-9af7-99be436b89c4>. Acesso em: 17 jan. 2017.

. Corte Constitucional da Colômbia afirma: A prostituição é um trabalho. Supremo Tribunal Federal. Notícias. Brasília/DF. 2017. Disponível em:

$<$ http://www2.stf.jus.br/portalStfInternacional/cms/destaquesNewsletter .php?sigla=newsletterPortalInternacionalNoticias\&idConteudo=273181 > . Acesso em: 17 jan. 2017.

. Corte Constitucional da Colômbia entende que não se pode exigir cartão militar de pessoas transexuais. Supremo Tribunal Federal. Notícias. Brasília/DF. 2017. Disponível em: $<$ http://www2.stf.jus.br/portalStfInternacional/cms/destaquesNewsletter .php?sigla=newsletterPortalInternacionalNoticias\&idConteudo=273185> . Acesso em: 17 jan. 2017.

CAMPOS, Carlos Alexandre de Azevedo. Dimensões do Ativismo Judicial do STF. Rio de Janeiro: Forense, 2014.

CAPPELLETTI, Mauro. Juízes Legisladores? Porto Alegre: Sergio Antonio Fabris Editor, 1993. 134 p. Tradução de Carlos Alberto Alvaro de Oliveira.

CEPEDA-ESPINOSA, M. J. Judicial Activism in a Violent Context: The Origin, Role, and Impact of the Colombian Constitutional Court.

Washington University Global Studies Law Review, v. 3, n. 4, p. 529700, 2004.

CHEVALLIER, Jacques. O Estado Pós-Moderno. Traduzido por Marçal Justen Filho. Belo Horizonte: Fórum, 2009. 
CIFUENTES MUÑOZ, Eduardo. Reflexiones sobre la influencia de la constitución española de 1978 en la constitución colombiana de 1991. In: SEGADO, Francisco Fernández (Org.). La Constitución de 1978 y el Constitucionalismo Iberoamericano. Madrid: Centro de Estudios Políticos y Constitucionales, 2013.

COLÔMBIA. Constituição (1991). Constitución Política de Colombia. Colômbia, 1991.

Ley Estatutaria de La Administracion de Justicia. Colômbia, 1996.

. Corte Constitucional. Sentencia n⿳o. C-004, de 07/05/1992.

Disponível em:

$<$ http://www.corteconstitucional.gov.co/relatoria/1992/C-004-92.htm $>$. Acesso em: 17 jan. 2017.

. Corte Constitucional. Sentencia C-113/93, de 25/03/1993.

Disponível em:

$<$ http://www.corteconstitucional.gov.co/RELATORIA/1993/C-113-

93.htm>. Acesso em: 17 jan. 2017.

GINSBURG, Tom. Judicial Review in New

Democracies: Constitucional Courts in Asian Cases. Cabridge:

Cambridge University Press, 2003.

MAZOTTI, Marcelo. Jurisdição Constitucional e Ativismo

Judiciário: análise comparativa entre a atuação do Supremo Tribunal Federal e da Suprema Corte estadunidense. 2012. 142 f. Dissertação Curso de Direito, Universidade de São Paulo, São Paulo, 2012.

MELLO, Celso Antônio Bandeira de. Discricionariedade e controle judicial. São Paulo: Malheiros, 2001. 
DESENHO INSTITUCIONAL E JUDICIALIZAÇÃO DA POLÍTICA NAS CORTES CONSTITUCIONAIS BRASILEIRA E COLOMBIANA

MENDES, Gilmar Ferreira; BRANCO, Paulo Gustavo Gonet. Curso de Direito Constitucional. 9. ed. São Paulo: Saraiva, 2014.

MUKHOPADHAYA, Kaushik. Jury Size and the Free Rider Problem. The Journal Of Law, Economics, And Organization, Oxford, v. 19, n. 1, p. 24-44, 2003.

NARANJO MESA, Vladimiro. Diez Años de la Corte Constitucional Colombiana. Anuario Iberoamericano de Justicia

Constitucional, Madrid, v. 5, p.277-290, 2001.

POSNER, Richard A.. Is the Ninth Circuit too Large?: A Statistical Study of Judicial Quality. The Journal Of Legal Studies, Chicago, v. 29, n. 2, p. 711-719, jun. 2000.

RAMOS, Elival da Silva. Ativismo Judicial: Parâmetros Dogmáticos. São Paulo: Saraiva, 2010.

UPRIMNY YEPES, Rodrigo. A JUDICIALIZAÇÃO DA POLÍTICA NA COLÔMBIA: CASOS, POTENCIALIDADES E RISCOS. Sur - Revista Internacional de Direitos Humanos, v. 6, p. 53-69, 2007.

DESENHO INSTITUCIONAL E JUDICIALIZAÇÃO DA POLÍTICA NAS CORTES CONSTITUCIONAIS BRASILEIRA E COLOMBIANA: UMA ANÁLISE

COMPARADA

INSTITUTIONAL DESIGN AND JUDICIALIZATION OF POLITICS IN THE BRAZILIAN AND COLOMBIAN CONSTITUTIONAL COURTS: A COMPARATIVE ANALYSIS

Submetido em: 2017- 10- 23 Aceito em: 2018-06-09 